\title{
Safety assessment of industrial locations under the effects generated by controlled explosions
}

\author{
Gabriel Vasilescu ${ }^{1 *}$, Florea Dinu $^{2}$, Attila Kovacs $^{1}$, Robert Laszlo ${ }^{1}$, and Claudia Miron ${ }^{1}$ \\ ${ }^{1}$ National Institute for Research and Development in Mine Safety and Protection to Explosion - \\ INSEMEX Petrosani, Department of Safety of Explosion and Pyrotechnic Articles, G-ral V. Milea \\ Street 32-34, Petrosani, Romania \\ ${ }^{2}$ Polytechnical University Timisoara, University P-ta Victoriei Street 2, Timisoara, Romania
}

\begin{abstract}
The identification and consideration of various potential hazards significantly reduce the accidents in the industrial locations where specific operations with explosive materials take place. The purpose of this study was to assess the effects generated by external explosions produced near an experimental steel frame building model. The novelty of the paper is the combination of experimental results on site with data from specialised databases of accidental explosions. These data were integrated using computer modelling to evaluate the risk associated with different hazardous situations (shockwave propagation, spreading of debris), and the effects on the location. The numerical simulations were performed using IMESAFR software, which is a quantitative risk assessment tool and can be used to calculate risk to personnel from commercial explosives facilities and operations. The results of the simulations were used to design the perimeter security within the site and the placement of the experimental model, considering the maximum expected blast charge. Considering the limited space available on site, the results of the simulations were very valuable and confirmed the tests that were already planned can be performed without any risk for personnel, nearby buildings and facilities.
\end{abstract}

\section{Introduction}

The starting point for effective design and management of occupational health and safety in the field of explosives for civil use consists in the reduction of the global risk for different accidental scenarios, respectively the reduction of occupational hazards, the risk of a terrorist attack and the risk of structural collapse [1]. These activities have the effect of optimising the activities to prevent accidents in the industrial locations where specific operations using explosive materials take place, as well as to protect the urban areas exposed to terrorist threats $[2]$.

There is a low probability of the occurrence of explosions in urban environments, but when they occur they represent major sources of risk for people's lives and the safety of constructions. When the charge is detonated in the proximity of main structural elements of construction, heavy local damages may occur, which, in turn, may extend and trigger a

\footnotetext{
* Gabriel Vasilescu: dragos.vasilescu@insemex.ro
} 
generalised collapse (also called progressive collapse). Progressive collapse, which in most cases causes more victims than the shockwave, or the fragmentation effect (of the explosive charge or the debris blown away from the building) may be prevented through different measures which aim to reduce the exposure, for instance by increasing the safety distance, as well as vulnerability by using structural systems with increased redundancy and continuity between elements $[3,4]$.

The capacity of a structure to resist different kinds of extreme actions without being damaged to an extent disproportionate to the original cause is called robustness and is required by the design codes and standards [5]. Raising awareness concerning these risks requires adequate measures during the design and construction of building structures [6]. The explicit analysis and design against explosions can pose difficulties (compared to other types of design), both in terms of load assessment (i.e. the maximum value of the resulted pressure or its variation on element or structure) and the effects on the materials and elements, for instance, the effect of the loading rate over the mechanical characteristics of steel or the explosion-structure interaction. As the stand-off distance from the explosion reduces, the effects on the building become more complex. In such a case, the use of numerical analyses may lead to more accurate results, especially when results are validated against experimental data $[7,8]$. As very few experimental studies have been carried out on resistance against blast of framed buildings, there is a high interest for such investigations.

The study presents the results of the safety assessment of an industrial site designed for specific operations using explosive materials $[9,10]$. On the site, explosive testing of a fullscale building model is planned. The results of the simulations were necessary to design the perimeter security within the site and the placement of the experimental model and video instrumentation, considering the maximum expected blast charge. The experimental results and data from specialised databases of accidental explosions were integrated using computer modelling to evaluate the risk associated with different hazardous situations (shockwave propagation, spreading of debris), and the effects on the location. The numerical simulations were performed using IMESAFR software [11], which is a quantitative risk assessment tool used to calculate risk to personnel from commercial explosives facilities and operations.

\section{Probabilistic risk assessment of technical infrastructures exposed to site explosions}

The synthesis of the methodology used in the study is based on the concept of risk [8], first described in 1662 by the French mathematician Blaise Pascal: "Our fear for the prejudice should be in direct proportion not only to the value of the prejudice but also with the probability of the generating event". Thus, the risk can be expressed using the following equation:

$$
\text { Risk = Event probability } \times \text { Severity }
$$

In order to take into account the risk specific to human health, a more complex version of the equation may be adopted, namely:

$$
\text { Risk }=\text { Event probability } \times \text { Severity } \times \text { Exposure }
$$

Equation (2) is a direct derivative of equation (1), where the probability of the event (in this case, the explosion) is expressed in terms of probability of the event and severity of consequences (the probability of fatality), also taking into consideration the presence of people, namely the exposure.

To estimate the probability of fatality for a person (per year), $P_{f}$, the following equation is used: 


$$
P_{f}=\mathrm{P}_{\mathrm{e}} \times P_{f / e} \times E_{p}
$$

where:

$P_{e}$ is the annual probability for an event (e.g. explosion) to occur on the site of the explosion (source type structure which implies the existence of explosive materials for specific operations).

$P_{f / e}$ is the fatality probability due to an event such as an explosion and the presence of at least one person.

$E_{p}$ is the exposure of one person in a source type location given the conditions of a welldefined time span (one year).

In addition to individual risk, consideration should be given to societal risk, which provides a mechanism to estimate the total number of people affected by the event. Thus, the term $E_{f}$, which may be applied to a group of people, represents the risk combined with the fatality of the people from the group (also called a group risk). $E_{f}$ can be defined as the sum of individual risks and offers a statistical perspective of the assessed scenario as a mathematical expectancy or an anticipated value (for instance the average number of deaths anticipated per year) as it is given by the following equation:

$$
E_{f}=\sum\left(\mathrm{P}_{\mathrm{e}} \times P_{f / e} \times E_{p}\right)
$$

\subsection{Event analysis}

The first term of the risk equation (4) is the probability of the event, Pe. This term is used to assess the probability of an event (e.g. explosion) to occur at a site, which also has a source type structure. The probability of the event may be estimated in several ways. The accuracy of results is expected to increase when historical data are available. An example is the international database of accidental explosions due to explosives for civil uses developed by two agencies with activity in the field, i.e. the Institute of Makers of Explosives (IME) and Department of Defense (DoD). This database was used in the study to develop a matrix of the probabilities Pe for operations dealing with explosions. Pe can be defined as a function of three parameters: the specific activity (the type of activity); the store of the explosive products by groups of products considering their compatibility from a destructive energetic point of view (sensitivity); environmental factors (external factors).

\subsection{Analysis of effects and consequences}

The second term of the risk equation (4) is the probability of fatality given by the type of explosion occurring in the presence of an exposed person, Pf|e. This term is determined by taking into consideration the possible lethal results at the level of the exposed site (exposed structure type) due to multiple hazardous mechanisms. The potential mechanisms of lethal accidents are analysed in parallel and may be grouped as follows:

- Overpressure/impact impulse (the explosion creates a shockwave described both through overpressure, and through the impact impulse);

- The structural response (overpressure and impact impulse specific to the exposed siteexposure type structure). Two consequences are therefore assessed: the fracture, separation, and projection of fragments from the structure (such as glass from windows) and the partial or total collapse of the building;

- The debris, i.e., the material composed of hazardous products, comes from three sources: main debris (explosive materials), secondary debris (at the level of a source type structure) and debris resulted after the impact (for instance from the crater which may be the result of the explosion); 
- The radiation/the thermal flux, used only for the hazardous division (HD) 1.3 explosives - mass fire [12].

The effects and consequences of each hazardous mechanism are taken into consideration sequentially in relation to the previously presented potential mechanism, respectively: (1) hazards generated at the level of the location (source type structure), (2) damages/conditions caused by the source type structure, (3) damages/conditions caused by the distance between the location (source type structure) and the exposure site (exposure structure) and (4) damages/conditions caused by the presence of the structure on the exposure site (exposure structure) - if any, before reaching the exposed person.

\subsection{Exposure analysis}

The individual exposure is determined by the probability for a person to be present when an unforeseen event occurs, e.g. an explosion (quantified through a value ranging between 0 and 1). The measurement units of a person's exposure may be exposure units per year, or, simpler, they may be expressed as the number of people when the exposure refers to more than one person present.

During the assessment process, the hazards corresponding to the exposed people are estimated based on different algorithms and models specific to each type of hazard. Most of the models are based on "typical" scenarios, with the exposure occurring at moderate distances and given by the quantity - distance criterion [13].

\section{Computer modelling of the explosion risk in the industrial locations with activity in the field of explosives for civil use}

Computer modelling was performed using the specialized software IMESAFR $2 \mathrm{v}$, which is a quantitative risk assessment tool used to calculate risk to personnel from commercial explosives facilities and operations. The analysis involves the following steps:

- Definition of the scenario, events analysis, and exposure. This step also includes user inputs to describe the scenario (for the industrial location which comprises the source type and exposure structures) and the existing net explosive weights, and determines the probability of the event, exposure, and efficiency;

- Overpressure/impact impulse, which determines the value of the pressure and the fatality mechanisms based on impact impulse;

- Structural response on the exposed site (exposure structures), which determines the level of damage in the structural and non-structural elements of the building, and the number of accidents resulting in deaths or injuries;

- Debris, i.e. material resulted from an explosion and projection of fragments, which determines the magnitude of the mechanisms of hazardous debris and accidents resulting in deaths or injuries;

- Radiation and thermal flux, which determines the importance of the fatality mechanism caused by the thermal factor - only for the HD 1.3 scenario (HD-Hazard Division; 1.3Explosive Types: Packaging with small fragments, No primary fragments, Unknown-defaults to packaging with small fragments, User defined explosive article);

- The quantification of the final results through analytical composition, aggregation and sum up mechanisms. In this step, the risk situations and the general uncertainty are assessed.

As an example, Figure 1 shows the input data related to explosives (Figure 1a), data related to the source type structures (Figure 1b), and data related to the source type and exposure type structures (Figure 1c). 


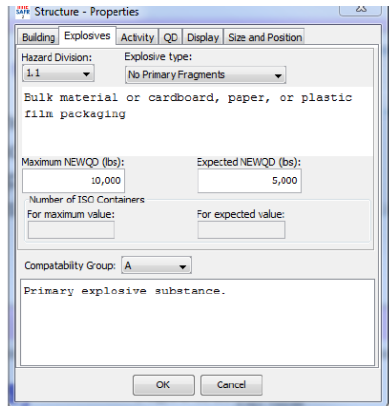

a)

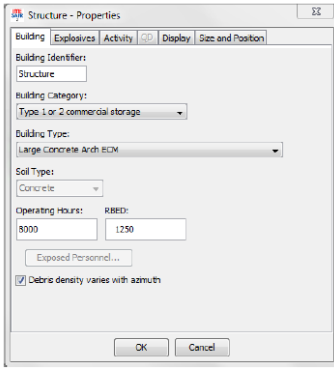

b)

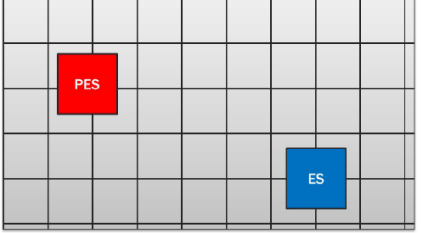

c)

Fig. 1. Types of data required at the input: a) data related to explosives; b) data related to the source type structures (PES); c) data related to the source type and exposure type structures (ES)

\section{Case study: the detonation of an explosive charge near an existing steel frame building located inside an explosive testing site}

The scope of the study was to simulate the explosion risk in the testing site and secure the staff and the assets during experimental blasting operations. The detonation of explosive charges was performed within the research project (PN-III-P2-2.1-PED-2019-1765) and aimed at evaluating the response of a steel frame building when charges of different sizes are detonated at different stand-offs from the building [14,15]. An experimental model, having two spans of $4.5 \mathrm{~m}$, two bays of $3.0 \mathrm{~m}$, and two stories of $2.25 \mathrm{~m}$ each, was built within the INSEMEX testing facility (see Figure 2).

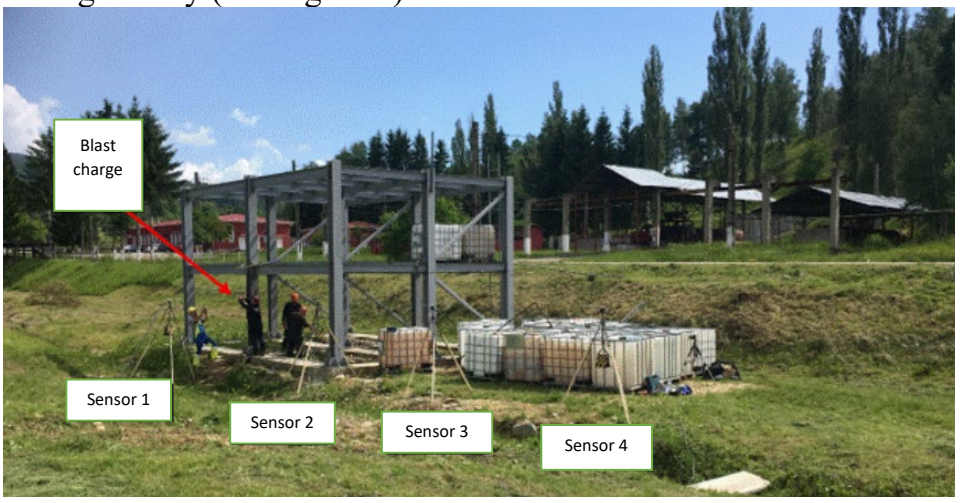

Fig. 2. Testing setup, steel frame structure and location of overpressure sensors (mounted in four different locations)

The type of explosive used for the experimental testing program is RIOMAX, delivered as $140 \mathrm{~g}$ cartridges wrapped in wax paper [16]. This is an explosive that is frequently used during blasting works. The product is sensitised with glass microspheres (providing it with greater power) and has a solid consistency and grey colour due to the aluminium found in its composition. RIOMAX has the same characteristics as dynamite but has the advantage that it does not contain glycerine nitrates and nitrogen oxides (NOx) emissions are low. 


\subsection{Evaluation of the pressure developed during the detonation of the charges in the proximity of the frame building}

Two experimental tests were carried out, in which two explosive charges were detonated in the proximity of the middle perimeter column of the structure.

The parameters of the first test were the following:

- $\quad$ mass of the explosive charge: $140 \mathrm{~g}$ ETNT (TNT equivalent);

- the distance between the explosive charge and the perimeter frame axis: $0.5 \mathrm{~m}$;

- the distance between the explosive charge and the ground: $1.8 \mathrm{~m}$ (1.5 m from the top side of the concrete foundation);

- the distance between the pressure sensor 1 and the explosive charge: $2.0 \mathrm{~m}$ from the middle column, collinear with the explosive charge;

- the distance between the pressure sensor 2 and the explosive charge: $4.5 \mathrm{~m}$, sensor placed in line with the explosive charge (distance to the perimeter frame axis $=0.5 \mathrm{~m}$ );

- the distance between the pressure sensor 3 and the explosive charge: $9.0 \mathrm{~m}$, sensor placed in line with the explosive charge and sensor 2 ;

- the distance between the pressure sensor 4 and the explosive charge: $13.5 \mathrm{~m}$, sensor placed in line with the explosive charge and sensors 2 and 3;

- $\quad$ all sensors were located at $1.8 \mathrm{~m}$ from the ground;

The pressure measurements were done using a KISTLER system, equipped with IEPE type sensors and LabAmp 5165A4 amplifiers. The pressure results at each location are presented in Figure 3.

For the second test, all parameters were kept the same, excepting the mass of the explosive charge, which was increased to $280 \mathrm{~g}$ ETNT (TNT equivalent). The pressure results at each location are presented in Figure 4.

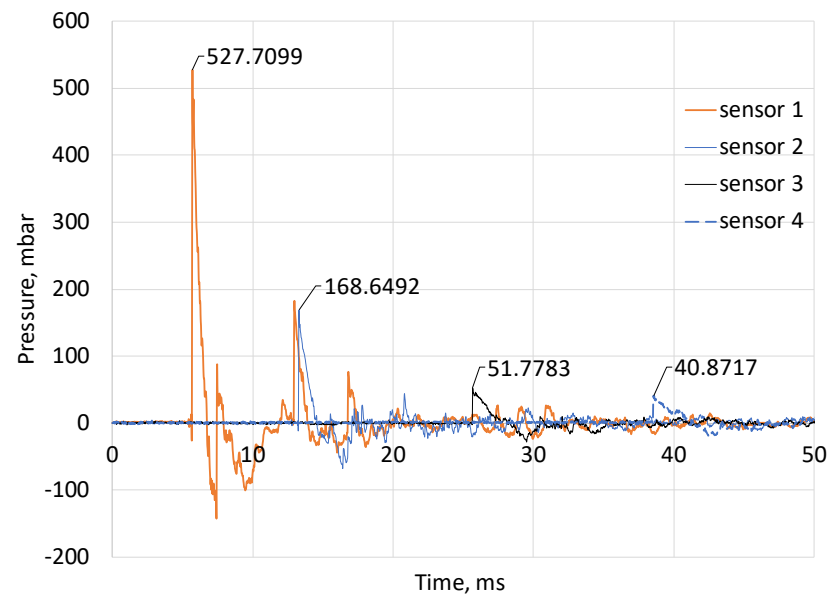

Fig. 3. Details of the pressure history and the peak values for each sensor, $140 \mathrm{~g}$ blast charge 


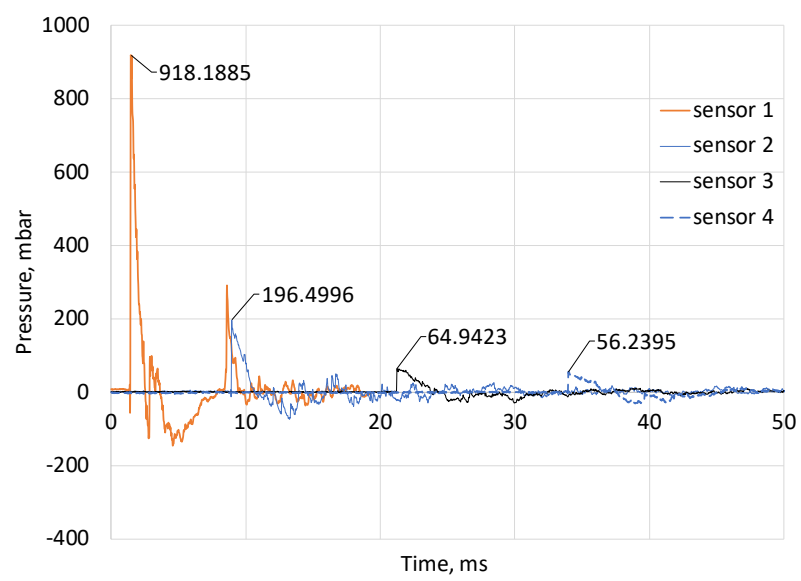

Fig. 4. Details of the pressure history and the peak values for each sensor, $280 \mathrm{~g}$ blast charge

The pressure values measured in the two experimental tests were used to calibrate the pressure law in the shockwave boundary, see Table 1. The shockwave peak pressureoverpressure, generated by the TNT equivalent charge, is a function which depends on the distance, weight of explosive charge and local conditions, and can be calculated using the following equation:

$$
P=A *\left(\frac{D}{(W)^{b}}\right)^{a}
$$

where: $\mathrm{P}=$ peak pressure of the shockwave generated by the explosion $(\mathrm{kPa}) ; \mathrm{A}=$ site constant (determined experimentally); a = site exponent (determined experimentally, always negative value) $b=$ site exponent for the weight of the explosive charge (determined experimentally); $\mathrm{D}=$ the distance between the explosive charge/TNT equivalent and the target $(\mathrm{m}) ; \mathrm{W}=$ the weight of the explosive charge, TNT equivalent $(\mathrm{kg})$.

Table 1. Calculation of experimental coefficients for the pressure law

\begin{tabular}{|c|c|c|c|c|c|c|}
\hline $\begin{array}{l}\text { Distance } \\
\text { between } \\
\text { explosive } \\
\text { charge } \\
\text { and } \\
\text { pressure } \\
\text { sensor } \\
\text { (m) }\end{array}$ & $\begin{array}{l}\text { Obstruction } \\
\text { coefficient for } \\
\text { incident wave, } \\
\text { determined } \\
\text { experimentally, } \\
\text { Cobstr }(*)\end{array}$ & $\begin{array}{l}\text { Weight of } \\
\text { the } \\
\text { explosive } \\
\text { charge, } \\
\text { TNT } \\
\text { equivalent } \\
\text { (kg) }\end{array}$ & $\begin{array}{l}\text { Aerial } \\
\text { overpressure } \\
\text { generated by } \\
\text { the } \\
\text { detonation of } \\
\text { the TNT } \\
\text { equivalent } \\
\text { explosive } \\
\text { charge }(\mathrm{kPa})\end{array}$ & $\begin{array}{l}\text { Aerial } \\
\text { overpressure } \\
\text { generated by } \\
\text { the } \\
\text { detonation of } \\
\text { the TNT } \\
\text { equivalent } \\
\text { explosive } \\
\text { charge (dB) }\end{array}$ & $\begin{array}{l}\text { Aerial } \\
\text { overpressure } \\
\text { generated by } \\
\text { the } \\
\text { detonation of } \\
\text { the TNT } \\
\text { equivalent } \\
\text { explosive } \\
\text { charge (bar) }\end{array}$ & $\begin{array}{l}\text { Values } \\
\text { measured } \\
\text { with } \\
\text { pressure } \\
\text { sensors } \\
\text { during } \\
\text { test (bar) }\end{array}$ \\
\hline 2 & 1 & 0.14 & 59.53 & 189.47 & 0.58755 & 0.527 \\
\hline 4.5 & 1 & 0.14 & 16.27 & 178.20 & 0.16053 & $\begin{array}{l}0.169 \\
0.187 \\
0.142\end{array}$ \\
\hline 9 & 1 & 0.14 & 5.37 & 168.57 & 0.05295 & $\begin{array}{l}0.049 \\
0.058 \\
0.047\end{array}$ \\
\hline 13.5 & 1 & 0.14 & 2.80 & 162.94 & 0.02768 & $\begin{array}{l}0.038 \\
0.042 \\
0.022\end{array}$ \\
\hline 2 & 1 & 0.28 & 86.16 & 192.69 & 0.85034 & 0.918 \\
\hline 4.5 & 1 & 0.28 & 23.54 & 181.42 & 0.23233 & $\begin{array}{l}0.196 \\
0.231\end{array}$ \\
\hline
\end{tabular}




\begin{tabular}{|l|l|l|l|l|l|l|}
\hline 9 & 1 & 0.28 & 7.77 & 171.78 & 0.07664 & $0.064 ;$ \\
& & & & & & 0.068 \\
\hline 13.5 & 1 & 0.28 & 4.06 & 166.15 & 0.04006 & $0.056 ;$ \\
& & & & & & 0.053 \\
\hline
\end{tabular}

$(*)$

- $\quad$ Cobstr $=8$ when there is a rigid obstacle between explosive charge and pressure sensor, and distance between charge and obstacle is less than $20 \mathrm{~m}$

- $\quad$ Cobstr $=5$ when there is a rigid obstacle between explosive charge and pressure sensor, and distance between charge and obstacle is between $200 \mathrm{~mm}$ and $500 \mathrm{~mm}$

- $\quad$ Cobstr $=1$ for direct exposure, no rigid obstacles and the reflector (steel element) is located at more than $500 \mathrm{~mm}$.

- $\quad$ Cobstr $=0.8$ (amplification effect) for direct exposure, and the reflector (steel element) is located at $200 \mathrm{~mm}$.

- $\quad$ Cobstr $=0.5$ (amplification effect) for direct exposure, no rigid obstacles and the reflector (steel element) is located at less than $10 \mathrm{~mm}$.

The equation (5) has the mass exponent of the explosion as 1/3 for open-air detonations. Using the peak pressure values recorded during the experimental tests, the parameters $A, a$, and $b$ were calculated, resulting in $\mathrm{A}=515 ; \mathrm{a}=-1.6 ; \mathrm{b}=1 / 3$. Using the values of $\mathrm{A}$, a, and $\mathrm{B}$, the formula for the variation of blast pressure may be approximated using the formula below:

$$
P=515 *\left(\frac{D}{(W)^{1 / 3}}\right)^{-1,6}
$$

Then, by using equation (6), the variation of pressure with distance was calculated for the two explosive charges, i.e. $140 \mathrm{~g}$ and $280 \mathrm{~g}$, respectively (see Figure 5).

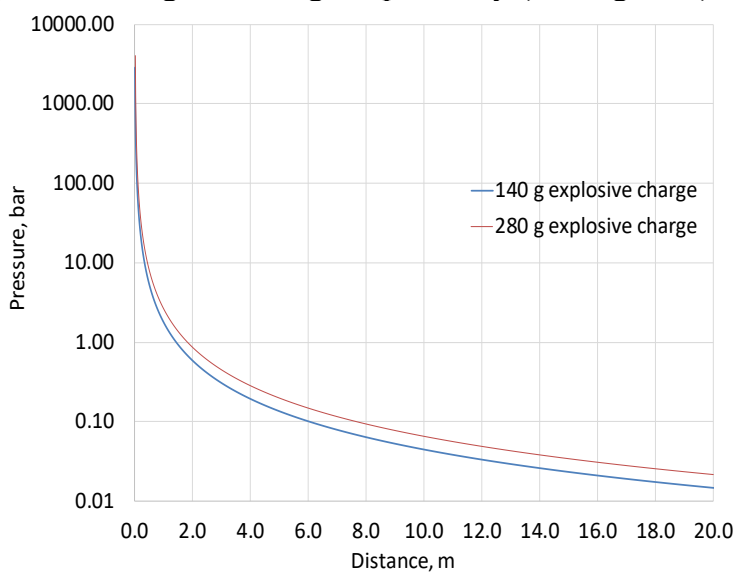

Fig. 5. - Pressure curves for $140 \mathrm{~g}$ and $280 \mathrm{~g}$ explosive charges (ETNT)

\subsection{Computer simulation of the damage level generated within the industrial site during experimental explosions}

The experimental explosions on the site were intended to use explosive charge of $2.52 \mathrm{~kg}$ ETNT. Therefore, in order to evaluate the safety of the testing program and prevent any damage or injuries to personnel within the industrial location, a computer simulation program was performed using one charge of $2.52 \mathrm{~kg}$ ETNT. For this explosive mass, three different results were provided: Effects against personnel generated by the overpressure; Effects against personnel generated by the debris; Cumulated effects due to overpressure and debris. 
The severity of the effects was classified using the pressure level, i.e: fatality, for overpressure $\mathrm{p} \leq 15.9 \mathrm{kPa}$; major injuries, defined as injuries requiring hospitalization, for an overpressure $15.9 \mathrm{kPa} \leq \mathrm{p} \leq 8.3 \mathrm{kPa}$; minor injuries, defined as injuries requiring medical treatment (beyond self-help), for an overpressure $8.3 \mathrm{kPa} \leq \mathrm{p} \leq 6.2 \mathrm{kPa}$.

Note that values of pressure less than $6.2 \mathrm{kPa}$ are considered tolerable and require no action.

The next figures plot the circular diagrams and contour maps for one blast charge only $(2.52 \mathrm{~kg})$, indicating the pressure limit for each region (i.e. fatality, major injuries, and minor injuries) and the corresponding radial distance measured from the point of detonation.

The circular diagrams have the following meaning (Figure 6):

- The $15.9 \mathrm{kPa}$ curve (i.e. 0.159 bar), whose circular area defines the fatality area (i.e. mortality area) for a distance from the explosive charge of $13.66 \mathrm{~m}(2.52 \mathrm{~kg}$ ETNT);

- The $8.3 \mathrm{kPa}$ curve (i.e. 0.083 bar) which, compared to the previous curve (15.9 $\mathrm{kPa})$, defines the circular area corresponding to the major injuries (irreversible), for a maximum distance from the explosive charge of $21.794 \mathrm{~m}(2.52 \mathrm{~kg}$ ETNT);

- The $6.2 \mathrm{kPa}$ curve (i.e. $0.062 \mathrm{bar}$ ), which, compared to the previous curve $(8.3 \mathrm{kPa})$, defines the circular area corresponding to the minor injuries (reversible), for a maximum distance from the explosive charge of $27.403 \mathrm{~m}(2.52 \mathrm{~kg}$ ETNT).

The contour maps have the following meaning (Figure 7):

- Fatality area (i.e. mortality) generated by the debris projection resulted during the detonation, comprised in the red area for a distance from the explosive charge of 6.579 $\mathrm{m}(2.52 \mathrm{~kg}$ ETNT);

- Major injuries area (i.e. irreversible) generated by the debris projection resulted during the detonation, comprised in the orange area for a distance from the explosive charge of $9.301 \mathrm{~m}(2.52 \mathrm{~kg}$ ETNT);

- Minor injuries area (i.e. reversible) generated by the debris projection resulted during the detonation, comprised in the orange area for a distance from the explosive charge of $13.479 \mathrm{~m}(2.52 \mathrm{~kg}$ ETNT);

The risk curves plotted for the experimental explosions have the following meaning in relation with the DoD provisions (Figure 8):

- The fatality risk area (area delimited by the first red dotted curve), for a distance from the explosive charge of $3.538 \mathrm{~m}(2.52 \mathrm{~kg}$ ETNT);

- The major injury risk area (area delimited by the second orange dotted curve), for a maximum distance from the explosive charge of $5.316 \mathrm{~m}(2.52 \mathrm{~kg}$ ETNT);

The minor injury risk area (area delimited by the third yellow dotted curve) for a maximum distance from the explosive charge of $7.325 \mathrm{~m}(2.52 \mathrm{~kg}$ ETNT).

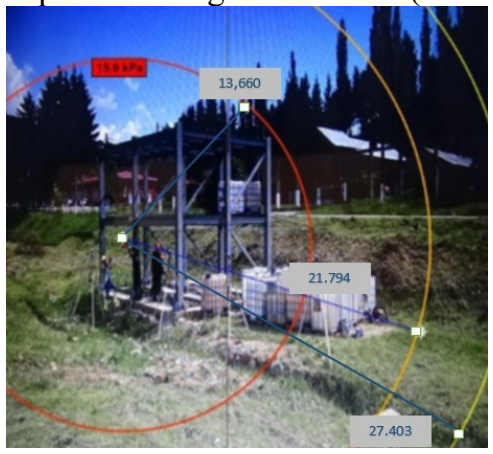

Fig. 6. Effects generated by the overpressure for charge of $2.52 \mathrm{~kg}$ ETNT 


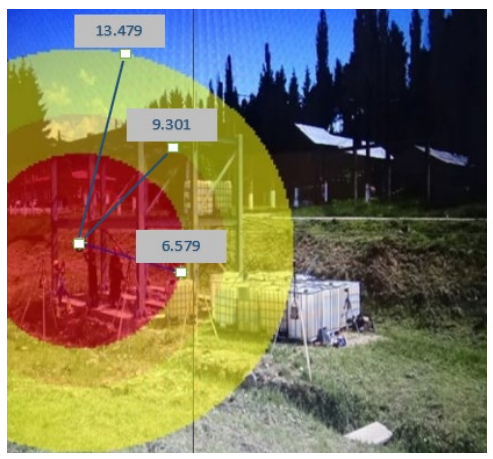

Fig. 7. Effects generated by the projection of debris for charge of $2.52 \mathrm{~kg}$ ETNT

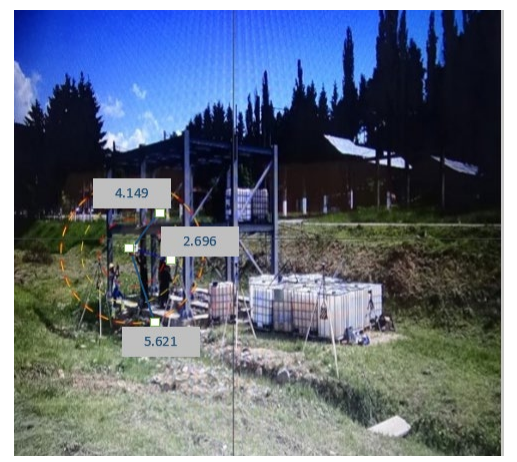

Fig. 8. Areas of risk for charge of $2.52 \mathrm{~kg}$ ETNT

\section{Conclusions}

The study presented in the paper aimed to estimate the possible levels of damage and the risk zones for the personnel within the perimeter of an industrial location used for specific operations involving explosions. The controlled explosions were intended as part of a research project aiming to predict the blast response of a steel framed building. After two preliminary small size charges were detonated in the proximity of the model, numerical simulation were performed to evaluate the areas of risk, check the placement of the test building and design the perimeter security considering charges of different sizes, up to the maximum expected blast charge (approximately $2.5 \mathrm{~kg}$ ETNT). The effects of explosions against personnel and nearby buildings and facilities took into account two main factors, i.e. the overpressure of the shockwave, which induces damages in buildings and can harm people (injuries, fatalities), and debris (mainly flying debris from the building), respectively.

The results of the simulations (circular diagrams of the overpressure curves, contour maps with the effects produced by the flying debris, and zones of risk) helped at controlling the testing program and reduce the risk to personnel, and also at proper placement of instrumentation (i.e. video cameras) and other assets vulnerable to overpressure or debris. The results of the numerical analysis were confirmed, and no accidents were recorded during the experimental tests.

\section{Acknowledgments}

This work was supported by two grants of the Romanian National Authority for Scientific Research and Innovation, CNCS/CCCDI - UEFISCDI: project PN 19010202 - CORE 
Programme "Development of technical and methodological infrastructure for testing and evaluation of security parameters specific to explosives for civil use and pyrotechnic articles" and project PN-III-P2-2.1-PED-2019-1765 (Contract no.279 PED/2020), within PNCDI III: "Explosion safety of building enclosing walls".

\section{References}

1. Cavender, F., Phillips, S., \& Holland, M. (2008). Development of emergency response planning guidelines (ERPGS). Journal of Medical Toxicology, 4(2), 127-131. https://doi.org/10.1007/BF03160967.

2. Rus, D., Vasilescu, G., Kovacs, A., Gheorghiosu, E., \& Jitea, I.-C. (2017). Improving the group decision by optimization of risk management for specific activities with explosives for civil use. Quality-Access to Success, 18, 41-46.American Institute of Chemical Engineers AIChE. (2000). Guidelines for Chemical Process Quantitative Risk Analysis, 2nd Edition (Second Edition). New York.

3. Aven, T. (2008). Risk Analysis: Assessing Uncertainties Beyond Expected Values and Probabilities. Wiley.

4. Bejinariu, C., Darabont, D.-C., Baciu, E.-R., Georgescu, I.-S., Bernevig-Sava, M.-A., \& Baciu, C. (2017). Considerations on Applying the Method for Assessing the Level of Safety at Work. Sustainability, 9(7), 1263. https://doi.org/10.3390/su9071263.

5. EN 1991-1-7. (2006). Eurocode 1 - Actions on structures - Part 1-7: General actions - Accidental actions. European Committee for Standardisation CEN.

6. Department of Defense DoD. (2016). UFC 4-023-03. Design of Buildings to Resist Progressive Collapse.

7. Dinu, F., Dubina, D., \& Marginean, I. (2015). Improving the structural robustness of multi-story steel-frame buildings. Structure and Infrastructure Engineering, 11(8), 1028-1041. https://doi.org/10.1080/15732479.2014.927509.

8. Mazurkiewicz, L., Malachowski, J., \& Baranowski, P. (2015). Blast loading influence on load carrying capacity of I-column. Engineering Structures, 104, 107-115. https://doi.org/10.1016/j.engstruct.2015.09.025.

9. American Institute of Chemical Engineers AIChE. (2000). Guidelines for Chemical Process Quantitative Risk Analysis, 2nd Edition (Second Edition). New York.

10. Darabont, D.-C., Moraru, R. I., Antonov, A. E., \& Bejinariu, C. (2017). Managing new and emerging risks in the context of ISO 45001 standard. Quality-Access to Success, 18, 11-14.

11. Ross, T., Tatom, J., \& et al. (2015). IMESAFR Version 2.0, Safety Assessment for Risk. Technical Manual. A-P-T Research Inc, USA: Institute of Makers of Explosives.

12. Explosives regulations. (2014). Explosives regulations 2014: safety provisions: guidance on regulations. Merseyside: Health and Safety Executive, HSE Books.

13. Department of Defense DoD. (2014). UFC 3-340-02. Structures to resist the effects of accidental explosions. Washington DC.

14. PN-III-P2-2.1-PED-2019-1675, within PNCDI III: "Explosion-proof safety of building enclosures. Executive Agency for Higher Education, Research, Development and Innovation Funding.

15. Gheorghiosu, E., Ghicioi, E., Kovacs, A., Vasilescu, G., \& Rus, D. (2017). Determination of the Delay Accuracy of the Components of Non-Electric Initiation Systems. Environmental Engineering and Management Journal, 16(6), 1283-1287. https://doi.org/10.30638/eemj.2017.135.

16. Kovacs, A., Vasilescu, G., Gheorghiosu, E., Rus, D., Jitea, I.-C., \& Bordos, S. (2017). Appropriate management of preventing actions on health and safety for testing activities of high explosives in confined environment. Quality-Access to Success, 18, 93-96. 